\title{
Investigating the Effectiveness of a Math Practice Paper in Teaching and Learning of Mathematics
}

\author{
David Kibe Muchiri' ${ }^{1}$, Phineas Zaberio Mawira² \\ ${ }^{1}$ African Institute for Mathematical Sciences, University of the Western Cape, South Africa. Email: davidkibe@aims.ac.za \\ ${ }^{2}$ Department of Mathematics \& Actuarial Science, Kenyatta University, Kenya. \\ Email: mawiraphineap.m@gmail.com
}

DOI: 10.29322/IJSRP.10.07.2020.p10357

http://dx.doi.org/10.29322/IJSRP.10.07.2020.p10357

\begin{abstract}
Mathematics is the backbone of modern science, majorly used to solve world problems. Mathematical proficiency is thus very crucial. A math practice paper (MPP) can become a powerful tool for polishing student's mathematical knowledge and reasoning skills. This paper explores the usefulness of a math practice paper in the teaching and learning of mathematics. It also examines effectiveness of various differentiated strategies of implementing the use of a math practice paper in a diverse classroom. A class of 30 high school students was involved in this study. Students were introduced to math practice papers using various strategies during a term of 14 weeks. Classroom tests and questionnaires were used as instruments for data collection. Results were analyzed and compared. A math practice paper done individually, and then discussed in mixed-ability groups under the teacher intervention was observed to contribute significantly to student achievement. Constant use of MPPs resulted to a positive math trajectory.
\end{abstract}

Key words: Math practice paper, Practice questions, Teacher intervention.

\section{Introduction}

Mathematics is almost becoming applicable everywhere in real life. Mathematicians who are able to apply mathematical knowledge and offer mathematical thinking ability are needed widely in many fields across the globe. The conceptualization and understanding of classroom mathematics is thus very crucial. However, majority of students across the world do not like mathematics [1]. The percentage of students who specialize in mathematical sciences in high school and colleges is quite low. One of the main reasons why students dislike mathematics is negative attitude [2]. Among other factors, negative attitude likely develops when a student consistently get low grades in math tests. Poor performance can seriously impact on a student's perception about math. Apart from passing knowledge, the teacher has to ensure all students have the right attitude. Is that possible? Good performance in math tests is one of the strategies of boosting morale of students. Good grades make students appreciate and love mathematics. There are various instructional strategies that can be used to teach mathematics. However, studies are still carried out across the world to determine the most efficient method for mathematics education. This research investigates the use of a math practice paper as a strategy towards improving performance in a math class.

For many years teachers and students have often relied on textbooks to teach and learn mathematics. However, this has never been sufficient enough to prepare students for math tests. Textbooks have not been able to provide sufficient problems that are thought provoking, applicable in real life and challenging to all learners. The teacher thus, has to employ different instructional resources and practices that fill this gap. There are diverse teaching resources that can be used including teacher notes, past papers, work sheets, practice papers, games and teaching activities. Proper planning of the usage of these resources can contribute significant gains in student achievement. A well planned resource should pose a problem that generates an essence of curiosity that will make learner want to discover more [3]. Nonetheless, due to diverse abilities and talents among students, no single instructional resource has been proven to achieve math proficiency on its own. The choice of resources to use is a bit challenging as the teacher tries to gratify the aspiration of every student. It is thus reasonably important to use differentiated math instructions to suit distinct aptitudes [4]. Differentiated math instructions motivate students and promote their logical thinking and reasoning. It also promotes retention of desirable knowledge and development of positive attitude. The objective of this paper is to explore the effective use of

This publication is licensed under Creative Commons Attribution CC BY.

http://dx.doi.org/10.29322/IJSRP.10.07.2020.p10357

WwW.ijsrp.org 
a math practice paper as a differentiated teaching resource. Math practice paper can be done individually or collectively in groups, with or without teacher intervention. There is a vast literature about group work, for instance [5] proposed the effective use of mixed-ability groups in maximizing collaboration and promoting positive interrelationship as students share ideas. Math practice paper can also be combined with other teaching resources and strategies to achieve desirable objectives.

\section{Math Practice Paper (MPP)}

A math practice paper is a paper consisting of well organized questions and answers that are applicable in real life. Questions in the practice paper are crafted in a systematic way, to start from simple to complex and made interesting and challenging to learners. Practice questions are mainly topical and exhaustive enough to cover all relevant concepts. This paper is supposedly prepared by the teacher to cover concepts already taught in class. Apart from revision, the main objective of a math practice paper is to boost conceptual understanding of mathematics and enhance accuracy and speed. Some of the characteristics and importance of an effective math practice paper are outlined below.

\section{Characteristic of a good Math Practice Paper.}

Effectiveness of a practice paper depends on its quality. A good practice paper should be:

- Interesting to make learner want to reply.

- Relevant and applicable in real life.

- Systematically organized to start from simple to complex.

- Clear and understandable, with no vagueness.

- Able to generate the spirit of curiosity and wanting to discover more.

- Able to provoke learner's reasoning and thinking.

- Able to suit learners' ability and academic level of education.

\section{Importance of a Math Practice Paper}

A math practice paper can have many key implications depending on its quality and usage. The following are some of its importance.

- A math practice paper consists of questions from concepts already taught in class. Working out these questions enhances content mastery. It gives learners an opportunity to demonstrate their understanding of contents.

- A math practice paper enables learners identify concepts/topics they have not mastered well and this persuade them to pay more attention on those areas they experience difficulties. Also, the teacher gets a chance to gather feedback about topics that have been successfully learnt and those that need to be reviewed.

- Practice papers give learners an opportunity to revisit and practice arithmetic procedures taught in class. This stimulates revision hence promoting retention of prior knowledge.

- Practice questions stimulate students' thinking and reasoning which develops their interest towards mathematics.

- A math practice paper encourages constant use of mathematical tools such as calculators, mathematical sets and mathematical tables. This makes students intensify on their accuracy, skills and speed, which help in reducing anxiety and phobia in math exams.

- Regular use of MPPs familiarizes learners with assessment standards for mathematics, which makes them appreciate, accept and believe that exams are fair.

- Constant exposure to practice papers leads to a positive trajectory in mathematics. This inculcates a desirable attitude towards mathematics.

\section{Role of the Teacher}

Effective teaching is not just determined by the quality of a resource but by the teacher success in using the resource. Thus, the following are the vital roles of the teacher intervention in the usage of MPP. Amid other responsibilities, teachers should;

- Plan and prepare relevant practice questions in advance.

- Set interesting and thought provoking questions that are applicable in real life.

- Prepare questions that suit the ability levels of learners.

- Set questions that create the desire to know more.

- Set questions in a way that will make learner want to reply.

- Ensure practice papers are availed to learners on time.

- Ensure all students attempt questions.

- Guide students where necessary. 
- Revisit areas that look difficult to learners.

\section{Methodology}

This research was carried out in one of the secondary schools in Kenya for duration of 14 weeks. A class of 30 students was involved. All students were female of average age 15 years. The academic level of students was above average. According to the culture of the school, a continuous assessment test is done fortnightly to assess student progress in mathematics. A test is done after every two weeks. In addition to the test, this study introduced weekly math practice papers that would help students prepare for the test. A math practice paper comprised of at least 20 questions with answers provided. These questions were sourced from concepts already covered by the teacher in class. Practice questions were made interesting and crafted well to start with simple to complex questions. Math practice papers were provided at least a week before the test. The following three strategies of administering practice papers were considered and feedback collected and compared. Every strategy was investigated within four weeks. Two tests were done within the four weeks and the average of the two recorded for analysis to determine the impacts of math practice papers on student achievement. Best performing and most improved students were rewarded. This research was carried out whilst students were studying topics on indices, logarithm and equations of a straight line, which are normally challenging and difficult to students. The teacher played a vital role of facilitating and ensuring an effective running of this study.

a) MPP without teacher intervention

In this strategy, math practice papers were introduced to students to help them revise for the tests. Students were left to workout practices questions on their own and mark for themselves. There was no teacher involvement apart from normal teaching in class. One of the merits of this strategy is that it promotes intrinsic motivation, self drive, self confidence and independence among learners. High achievers can take advantage of this strategy to prepare adequately to outshine others. However, some students when not monitored may end up doing nothing about the paper. Moreover, the strategy can disadvantage less-able learners when left to work on their own.

b) MPP with teacher intervention

In this strategy, a math practice paper was provided to students to work out the problems and the teacher got involved in supervision and monitoring the progress. Students were instructed to attempt all the questions on their own. The teacher intervened to guide students on the most challenging questions. The main role of the teacher here, was to ensure all students attempted all the questions in MPP. With the teacher involvement, students get a chance to consult and confirm their workings. This inculcates confidence to students. In addition, every learner gets involved as the teacher monitors their progress. This is a plus to the overall mean score. The teacher on the other hand, gets an opportunity to find out challenging areas that may need review.

c) MPP in group work with teacher intervention

Here, students were provided with MPP and instructed to attempt all the questions individually under the supervision of the teacher. They were then placed in mixed-ability groups of four to collaborate, share ideas and assist each other in solving the difficult problems. The teacher got an opportunity to observe group discussions and guide where necessary. The teacher ensured all the questions were thoroughly done. Students got an opportunity to collaborate, share ideas and validate their work. Though time consuming, group discussions promote maximum participation and improve learning experiences [5].

At the final stage of the study, a questionnaire was administered to find out students' response about effectiveness of math practice papers. It was given to all 30 students, who agreed to participate voluntarily in this survey. The questionnaire was composed of five questions. Aspects of assessment were categorized as; strongly agree, agree, disagree and strongly disagree.

\section{Result and Discussion}

In this section, the effects of math practice papers on student achievement are analyzed and discussed. Figure 1 shows mean scores of tests done on various strategies of implementing MPPs. The least mean score was recorded when math practice papers were not yet introduced. This is due to the fact that students did not have enough materials to use for revision. Most likely students relied only on textbooks and classroom notes for revision which are not sufficient. On introduction of MPPs, the mean score rose significantly by a margin of 7.27. This clearly depicts that math practice papers had a positive impact on student performance. Math practice papers gave students an opportunity to attempt and familiarize themselves with questions and the way they are set in an exam. However, not all students performed well when left to attempt questions on their own without teacher intervention. This is clearly seen in figure 1

This publication is licensed under Creative Commons Attribution CC BY.

http://dx.doi.org/10.29322/IJSRP.10.07.2020.p10357

WWW.ijsrp.org 
and 2. This is due to the fact that lack of follow up by the teacher makes some student relax and perhaps opt not to attempt questions. This can bring the mean score down.

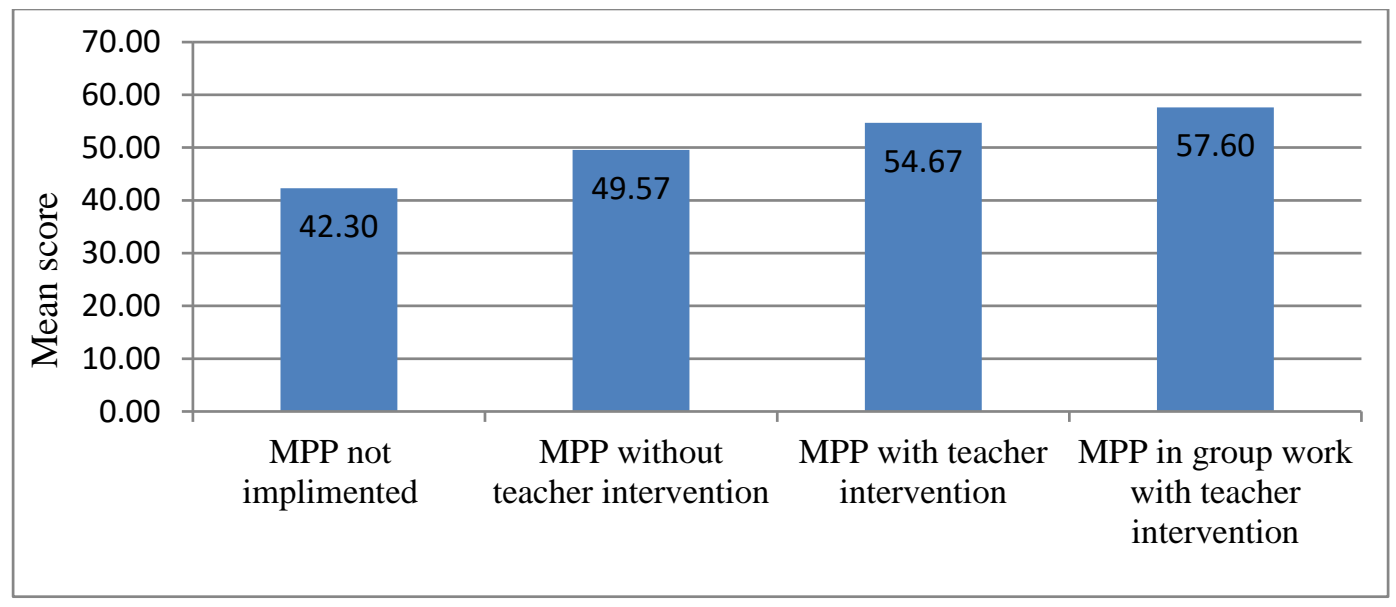

Figure 1: Mean scores of various strategies of implementing MPP.

When the teacher was involved, student performance rose to 54.67 as seen below. Apart from guiding where necessary, the teacher ensured all students attempted all the questions in the paper. This gave a positive result which shows that teachers play a big role when it comes to implementation of math practice papers. Math practice paper done in groups with teacher intervention gave the best score of 57.60. Students were instructed to attempt all questions individually after which they were placed in mixed-ability groups for discussion. Students had an opportunity to shear ideas, assist each other as well as validate their answers. This accelerated the average performance of students. As seen in Figure 2, majority of the students in this strategy scored between 60-79 marks. The teacher played the role of facilitating and guiding where necessary. The teacher factor is clearly evident on student performance.

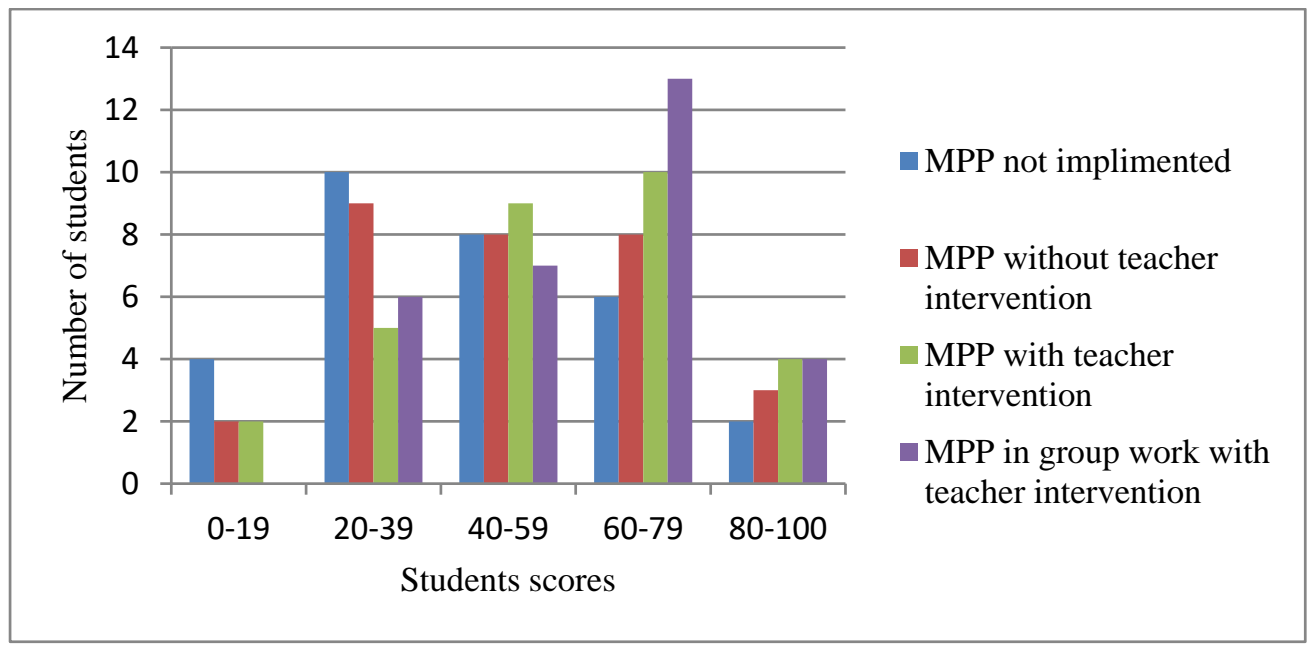

Figure 2: Scores achieved by students in various strategies of implementing MPPs.

Figure 3 and 4, below show the responses of a survey filled in by all students. From Figure 3, it is clearly seen that MPPs are more effective when done in groups with teacher intervention. This matches the result of the tests. We can thus conclude that the result of the survey is in good agreement with the result of the tests. 
Teaching maths is more effective when MPPs are

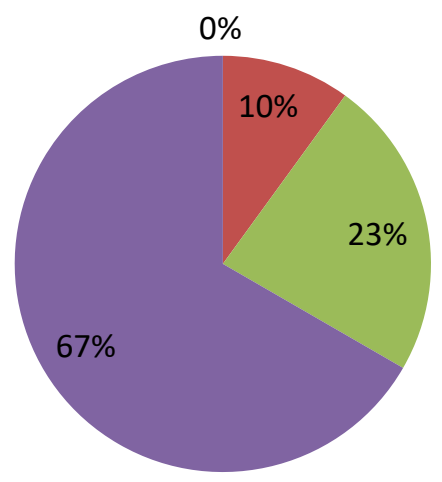

Not used

- Used without teacher intervention

- Used with teacher intervention

- Done in groups with teacher intervention

Figure 3: Students responses to Q1 of the questionnaire.

Majority of students preferred working out practice questions in groups under teacher intervention. Mixed-ability groups make learners benefit maximally through collaboration and exchange of ideas. Students get an opportunity to showcase their expertise as others get a chance to validate their solutions.

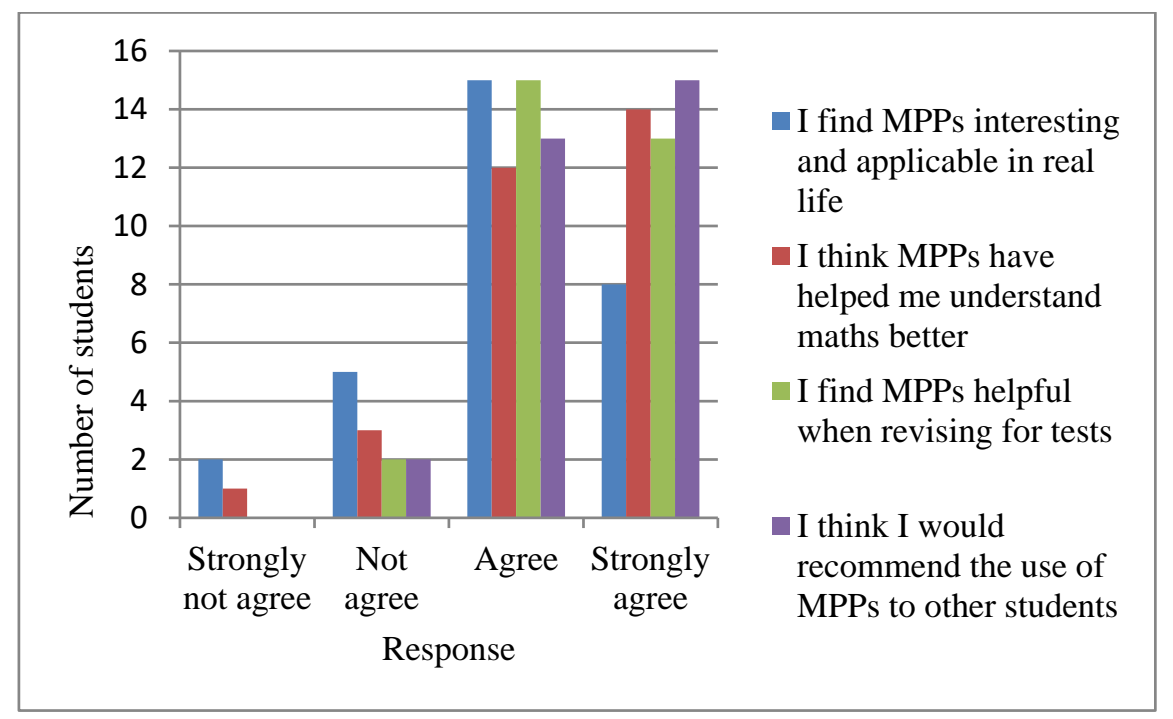

Figure 4: Students responses to Q2-Q5 of the questionnaire.

From the responses in Figure 4, it is deduced that introduction of math practice papers was helpful. Students acknowledged that practice papers contributed positively to their academic performance. Majority of the students gave positive responses to all the questions. This evidently shows that, constant exposure of MPPs instills a desirable attitude among learners which eventually leads to a positive math trajectory. A math practice paper, thus, can be used together with other instructional methods to enhance the teaching and learning of mathematics.

\section{CONCLUSION}

Mathematics is increasingly becoming the driving engine of careers and innovations across the world. Mathematical proficiency is thus vital in mathematics education. A quality math practice paper and the teacher success in implementing its use, can contribute substantially in student proficiency. Among other importance, a practice paper reinforces learning by promoting retention of prior 
knowledge, enhancing logical thinking and reasoning, and developing a desirable attitude towards mathematics. This research focused on the usefulness and the implementation of a practice paper in a diverse classroom. It was observed that tests done after math practice papers were introduced recorded significant improvement in the overall mean score of the class. This was in good agreement with the result of the survey. Majority of students preferred working out practice problems in small groups under teacher intervention. Teacher intervention had a positive impact on student performance. Thus, it is evident that the role of a teacher in defining conditions and method of using a resource is fundamentally important in mathematics education. It was clearly observed that a math practice paper done individually followed by a group discussion under teacher intervention was very effective and convenient to students. Constant exposure to practice papers led to a positive trajectory which inculcated a desirable attitude towards mathematics. Therefore, it is convincing that a well set and planned math practice paper combined with other instructional resources and practices can be used as a differentiated teaching strategy towards achieving math proficiency.

\section{References}

[1] Gafoor KA, Kurukkan A. Why High School Students Feel Mathematics Difficult? An Exploration of Affective Beliefs. Online Submission. 2015 Aug.

[2] Hannover B, Kessels U. Self-to-prototype matching as a strategy for making academic choices. Why high school students do not like math and science. Learning and instruction. 2004 Feb 1;14(1): 51-67.

[3] Shahrill M. Review of effective teacher questioning in mathematics classrooms. International Journal of Humanities and Social Science. 2013 Sep; 3(17): 224-31.

[4] Benders D, Craft T. The effect of flexible small groups on math achievement in first grade. Networks: An Online Journal for Teacher Research. 2016; 18(1), 724-.

[5] Muchiri DK, Njenga MC. Investigating Various Grouping Strategies in Teaching and Learning of Mathematics. International Journal of Advances in Scientific Research and Engineering. 2020; 6(3): 227-232. 